\title{
Plant cover associated with aboveground net primary productivity (ANPP) mediates insect community composition in steppes of Northwest China
}

\author{
Authors: Zihua Zhaoa, Gadi V.P. Reddy, Shuhua \\ Wei, Mengmeng Zhu, Kaiyang Zhang, Hongqian Yu, \\ Zhanjun Wang, Qi Jiang, and Rong Zhang
}

NOTICE: this is the author's version of a work that was accepted for publication in Journal of AsiaPacific Entomology. Changes resulting from the publishing process, such as peer review, editing, corrections, structural formatting, and other quality control mechanisms may not be reflected in this document. Changes may have been made to this work since it was submitted for publication. A definitive version was subsequently published in Journal of Asia-Pacific Entomology vol. 21, issue 1, March 2018, DOI\#10.1016/i.aspen.2018.01.017

Zihua, Zhao, Gadi V.P. Reddy, Shuhua Wei, Mengmeng Zhu, Kaiyang Zhang, Hongqian Yu, Zhanjun Wang, Qi Jiang, and Rong Zhang. "Plant cover associated with aboveground net primary productivity (ANPP) mediates insect community composition in steppes of Northwest China." Journal of Asia-Pacific Entomology 21, no. 1 (March 2018): 361-366. DOI: 10.1016/ j.aspen.2018.01.017.

Made available through Montana State University's ScholarWorks scholarworks.montana.edu 


\title{
Plant cover associated with aboveground net primary productivity (ANPP) mediates insect community composition in steppes of Northwest China
}

\author{
Zihua Zhao $^{\mathrm{a}, \mathrm{b}, *}$, Gadi V.P. Reddy ${ }^{\mathrm{c}}$, Shuhua Wei ${ }^{\mathrm{b}}$, Mengmeng Zhu ${ }^{\mathrm{b}}$, Kaiyang Zhang ${ }^{\mathrm{a}}$, \\ Hongqian Yu ${ }^{\mathrm{d}}$, Zhanjun Wang ${ }^{\mathrm{d}}$, Qi Jiang ${ }^{\mathrm{d}}$, Rong Zhang ${ }^{\mathrm{b}, * *}$ \\ a Department of Entomology, College of Plant Protection, China Agricultural University, Beijing 100193, China \\ ${ }^{b}$ Institute of Plant Protection, Ningxia Academy of Agriculture and Forestry, Yinchuan 750021, China \\ ${ }^{\mathrm{c}}$ Montana State University, Department of Research Centers, Western Triangle Agricultural Research Center, 9546 Old Shelby Road, P.O. Box 656, Conrad, MT 59425, \\ USA \\ dinstitute of Desertification Control, Ningxia Academy of Agriculture and Forestry, Yinchuan 750021, China
}

\begin{abstract}
A B S T R A C T
Temperate steppe is one of the most important natural habitats for the conservation of arthropod and bird biodiversity across the Eurasian Tectonic Plate. Since 1950, fragmentation of the steppe habitat has caused a loss of biodiversity and degradation of the species communities found in natural steppe. Therefore, in this study, both plants and insects were sampled at 56 sites in the steppe biome of northwestern China to explore the effects of plant community on insect community composition and diversity. The insect community structure varied in the four different steppe types (meadow steppe, typical steppe, desert steppe, and steppe desert). Plant cover (diversity) was an important driving force, which could enhance number of families and abundance of an insect community. Aboveground net primary productivity and water content of plants had no significant effects on insect community, although the plant community as a whole did mediate insect composition and community structure. Future research should explore the ecological role of particular functional groups in plant and insect communities. Supplemental sowing to improve plant diversity in steppe habitat may be another strategy to enhance biodiversity and achieve sustainable management.
\end{abstract}

\section{Introduction}

Temperate steppe is one of the most important habitats for the conservation of arthropods and bird biodiversity across the Eurasian Tectonic Plate (Dengler et al., 2014; Santana et al., 2017). Since 1950, a continuous loss and fragmentation of steppe has been reported due to conversion to arable farmland and exploitation of natural resources (particularly minerals and coal) in China (Deak et al., 2016). These processes have been accompanied by a rapid shift in insect communities that are highly dependent on the micro-environment of the steppe (Rangel-Landa et al., 2015). Although a series of ecological restoration measures have been implemented to recover ecosystem function and biodiversity in China (Palmer et al., 2014; Barral et al., 2015), but there have been few studies exploring the effects of such conservation strategies on insect communities across different steppe types in China (Eo et al., 2016).

In recent years, the relationship between insect composition and ecological function (e.g. biological control and pollination) has received substantial attention from ecologists around the world (Maser, 2013). A number of field experiments have found that conservation measures such as enclosure to increase plant cover improve arthropod diversity and this diversity is associated with multiple ecosystem functions (Liere et al., 2017). According to the mass ratio hypothesis, the functional properties of the dominant species within a given ecosystem plays a larger role in sustaining ecosystem function than does the number of species or community richness (Fanin et al., 2013; Tardif et al., 2014). In addition, the mass ratio hypothesis suggests that ecosystem function depends on the functional properties of common species, rather than all the species found in a given ecosystem (Lange et al., 2015). Thus, biological community composition is critical in promoting ecological function through improving the relationships among arthropod species (Fujii et al, 2017). However, Prieto et al. (2015) has raised the complementary effect, which suggests that different species in a community could have a coupling interaction (many species could contribute on one specific ecosystem function). High biodiversity could also facilitate ecosystem function according to the insurance hypothesis (Yachi and 
Loreau, 1999). In any case, arthropod community composition and structure are a critical component of any ecosystem (Ebeling et al., 2014).

Empirical ecological theory and field experiments have generally found a positive relationship between the diversity of plants and insects (Moreira et al., 2016). In the past a few decades, two mechanisms have been suggested to explain this phenomenon (Haddad et al., 2009; Zhao et al., 2013). First, most herbivorous insects (90\%) have a specific, specialized host (Branco et al., 2015), and so the species number of insects should increase with increasing plant richness. Many field experiments have supported this resource specialization hypothesis (Forister et al., 2015). Secondly, high plant richness may enhance aboveground net primary productivity (ANPP), as seen in some field experiments, and therefore the community should be able to support more herbivorous insect individuals and species because of the increased level of available resources of ANPP (Souza et al., 2016). An increase in the numbers of individuals of various herbivore insect species would further support more natural enemy species including predators and parasitic wasps. Recent field research has shown that plant species diversity associated with genetic diversity has cascading effects on insect community and ecosystem function (Richards et al., 2015). Some studies have been reported a link between plant community diversity, both in terms of the functional groups and species composition, and insect community structure (Rossetti et al., 2017).

Steppe habitat accounts for about $40 \%$ of China and $>70 \%$ of the land area in northwestern China (Qin et al., 2016; Zhang et al., 2017). There were four types of steppe in China: meadow steppe, typical steppe, desert steppe and steppe desert. Despite an increased interest in and significant research on the function and ecosystem services provide by insect communities, there is still a general lack of information on insect communities in the Chinese steppe (Zhu et al., 2015; Zhao et al., 2016). Since 2000, the Chinese government has adopted a series of enclosure conservation measures to increase plant cover and ANPP (Li et al., 2015). However, there have been few studies on the effects of this enclosure conservation system on insect biodiversity. In this study, we examined the effects of host-plant diversity and functional groups on the species composition, ecosystem function, ANPP and species richness of the associated insect community. Specifically, we aimed to answer the following questions: 1 ) what differences existed in insect composition and diversity among different steppe types and diversity characteristics, and 2) if ANPP associated with plant diversity affected insect composition and related ecological function.

\section{Materials and methods}

\section{Study area}

The study was conducted in the Ningxia Hui Autonomous Region in northwestern China that includes four different steppe types (meadow steppe, typical steppe, desert steppe and steppe desert). These four steppe types account for $>90 \%$ of the steppe area in Ningxia Hui Autonomous Region.

The meadow steppe was mainly distributed in South Ningxia (Liupan mountain and Nanhua mountain), and comprises about 88,700 ha. Yearly precipitation in meadow steppe ranges from 350 to $450 \mathrm{~mm}$ and the effective accumulated temperature $\left(\geq 10^{\circ} \mathrm{C}\right)$ ranges from 1800 to 2000 day degrees. In meadow steppe, grass height is $60-80 \mathrm{~cm}$ and ground cover is $60-85 \%$, while the ANPP per ha is $3375-6000 \mathrm{~kg}$.

Typical steppe is mainly distributed in Yunwu mountain and Yueliang mountain, comprising about 635,920 ha. Yearly precipitation in typical steppe ranges from 250 to $450 \mathrm{~mm}$ and grass height is $30-50 \mathrm{~cm}$. The effective accumulated temperature $\left(\geq 10^{\circ} \mathrm{C}\right)$ in typical steppe is $1600-1800$ day degrees.

Desert steppe, which is the dominant steppe type (accounting for $1,443,030 \mathrm{ha}$ ) in China, is mainly found in Xiang mountain and Yanchi.
Yearly precipitation in desert steppe is below $200 \mathrm{~mm}$ and the main vegetation is drought grass and shrub. The effective accumulated temperature $\left(\geq 10^{\circ} \mathrm{C}\right)$ in typical steppe is $1500-1700$ day degrees.

Finally, steppe desert is mainly found in central Ningxia (Zhongwei), and accounts for about $226,970 \mathrm{ha}$. Yearly precipitation in steppe desert is $100-150 \mathrm{~mm}$ and the main vegetation is strong drought shrub and semi-shrub.

In the whole steppes, a total of 56 sites (28 sites in desert steppe, 19 sites in typical steppe, 6 sites in meadow steppe and 3 sites in steppe desert) were selected for vegetation and insect investigation from July 20 to August 20 in 2015 and 2016. All experimental sites had been completely enclosed since 2006 to eliminate stochastic disturbance and human activity like grazing.

\section{Insect sampling}

At each sampling site, five yellow sticky cards $(210 \mathrm{~mm}$ wide and $297 \mathrm{~mm}$ length) were deployed using a random five-point method (Zhao et al., 2015a, 2015b) from August 10 to August 20 of 2016. At each point, a single yellow card was tagged $30 \mathrm{~cm}$ above the ground to a stick inserted $15 \mathrm{~cm}$ into the ground. After ten days, all yellow cards were collected and taken back to the laboratory, where they were kept at $-20^{\circ} \mathrm{C}$ to avoid deterioration of samples. All insects were identified to Family level (Hemiptera, Hymenoptera, Diptera, Lepidoptera, Coleoptera, and Neuroptera) according to morphological characteristics.

\section{Vegetation sampling}

For the plant community, at each sampling site, three random quadrats $(1 \times 1 \mathrm{~m})$ were selected for sampling. In each quadrat, we measured three variables including cover, ANPP and water content of plants. Plant cover was estimated using the projection method and visual investigation (one component of four degrees and one determination method). For the plant cover data, we recorded species identity and frequency within each quadrat. All plants can be identified to species level. Finally, we cut off all above-ground plant tissues in the quadrat and took to the laboratory in a paper bag where they were dried in an oven to determine the dry ANPP and, by reference to wet vs dry weights of samples, we estimated the water content of the plants in the aggregate (all species in the quadrat at their occurrence densities).

\section{Statistical analysis}

We calculated the mean number ( \pm SE) of individuals in each insect family per yellow card. Shannon-Wiener Index $\left(H^{\prime}=\sum_{i=1}^{k}\left(p_{i}\right)\left(l_{n} p_{i}\right)\right.$ were used to estimate the family diversity of the insect community, which was an empirical parameter of the insect community. ANOVA was used to compare the differences of insect diversity and abundance among four steppe types. Euclidean distance was used to calculate the distance of family composition between different steppe types using $\mathrm{R}$ 3.4.1 (R Development Core Team, 2016). In addition, back-step regression was used to examine the relationship between plant and insect community. As plant cover had a significant collinear relationship with plant diversity, only plant cover was kept as a variable, while plant diversity was deleted in the further regression analysis. All raw data underwent logarithmic transformation before linear regression analysis. All analyses were performed using the statistical software R 3.4.1 (R Development Core Team, 2016) with the "MASS" packages.

\section{Results}

A total of 10,974 individual insects belonging to 45 families were collected in the four steppe types collectively. There were $\mathbf{4 5}$ and 44 families in meadow steppe and typical steppe, respectively, while desert steppe had 40 families and steppe desert had just 18 (Fig. 1A). Meadow steppe also had the highest diversity indices $(2.31 \pm 0.54)$ while 

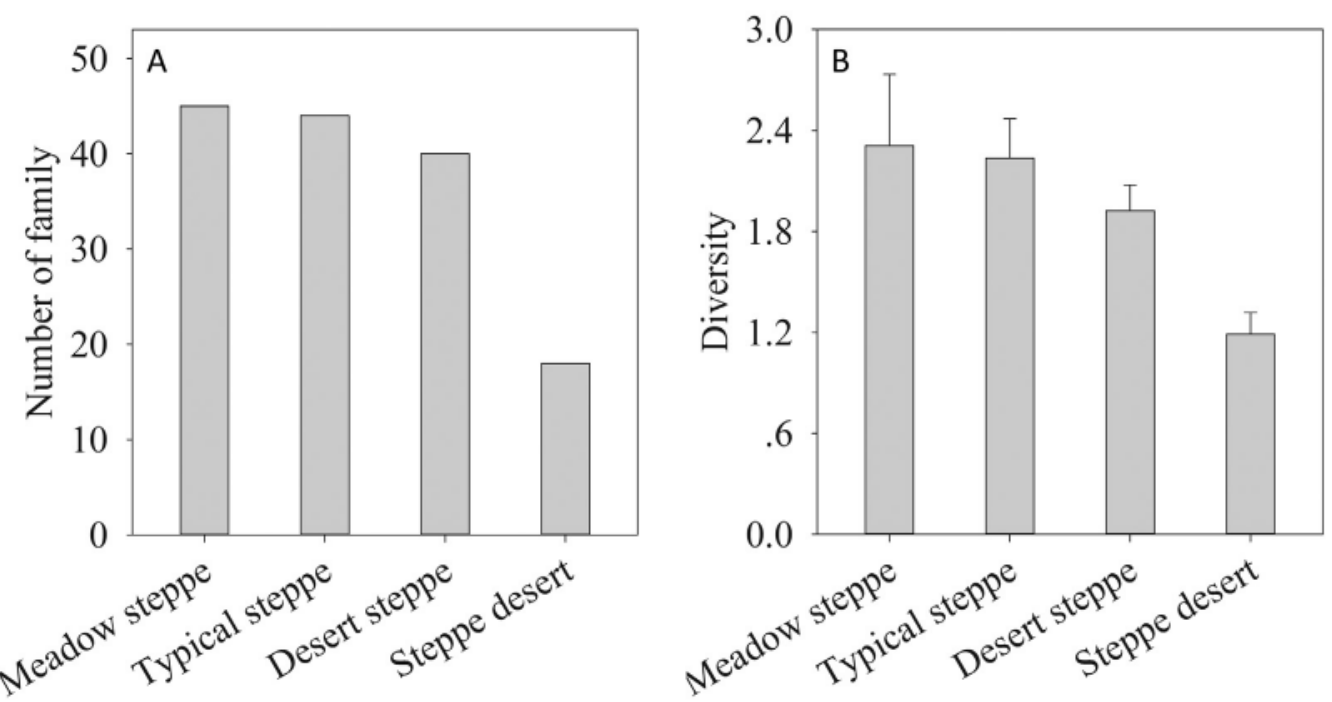

Fig. 1. The average number of families per site and family diversity of insect communities among sites within different steppe types (meadow steppe, typical steppe, desert steppe and steppe desert) in Ningxia, northwestern China. (A, average number of family in each steppe type B, diversity of insect family). steppe desert had the lowest diversity $(2.28 \pm 0.31)$. The diversity indices of typical steppe and desert steppe were $1.97 \pm 0.20$ and $1.25 \pm 0.19$, respectively (Fig. 1B).

The abundance of each insect family varied in each steppe type (Fig. 2). In both meadow steppe and typical steppe, the Muscidae, Chalcididae, Ichneumonidae and Braconidae were the dominant insect families while Aphididae, Ichneumonidae, Braconidae and Muscidae were the dominant families in desert steppe. In steppe desert, individuals of Aphididae were the least prevalent which was a significant difference with other steppe types (Fig. 2). Meanwhile, insect individuals in the Meloidae, Tettigoniidae, Satyridae and Cicindelidae were the least prevalent among the 44 families in meadow steppe. The Euclidean distance between meadow steppe and steppe desert was largest while desert steppe and steppe desert had the least distance between them (Table 1).

Plant cover was found significantly correlated to increase in the Shannon-Wiener diversity of insect families in each steppe type's insect community $\left(F_{1,55}=2.253, p=0.0283\right.$ ) (Table 2). Plant cover also had a significant effect on the ANPP $\left(F_{1,55}=6.632, p=0.012\right)$ and water content of plants $\left(F_{1,55}=15.11, p<0.001\right)$, both of which could be
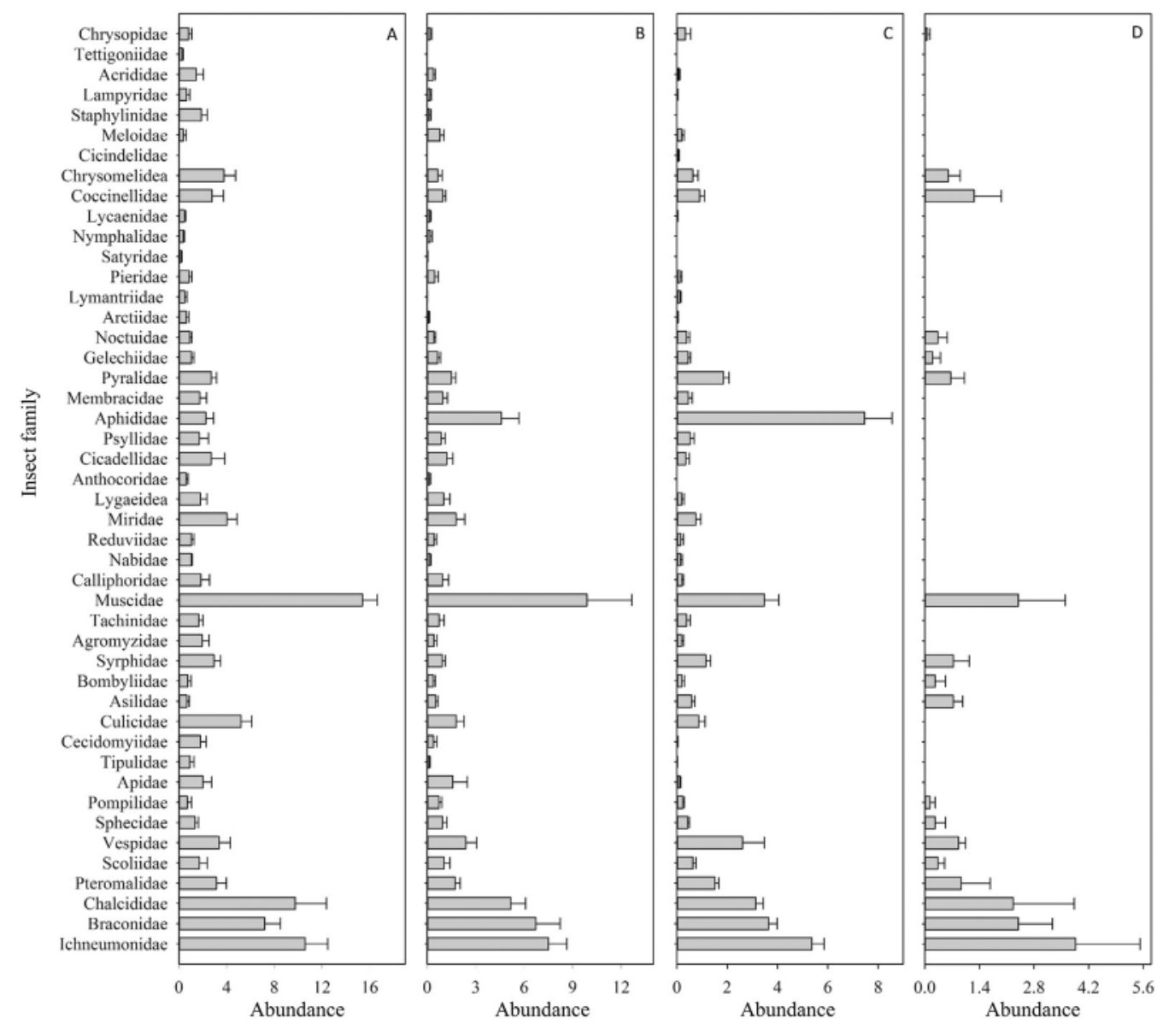

Fig. 2. The family distribution and abundance of individuals within families in insect communities in different steppe types in Ningxia, northwestern China (A: meadow steppe, B: typical steppe, C: desert steppe and D: steppe desert). 
Table 1

Matrix of similarity relation (Euclidean distances) among the four different steppe types in Northwest China

\begin{tabular}{lllll}
\hline & Meadow steppe & $\begin{array}{l}\text { Typical } \\
\text { steppe }\end{array}$ & $\begin{array}{l}\text { Desert } \\
\text { steppe }\end{array}$ & Steppe desert \\
\hline Meadow steppe & 1.00 & & & \\
Typical steppe & 124.04 & 1.00 & & \\
Desert steppe & 341.85 & 75.93 & 1.00 & 1.00 \\
Steppe desert & 423.98 & 138.78 & 69.8 & \\
\hline
\end{tabular}

described by linear regressions (Table 2, Fig. 3). However, the ANPP and water content of plants had no significant correlation with insect family diversity (Table 2). Furthermore, plant cover was significantly correlated with the number of individuals caught per sticky card $\left(F_{1,55}=4.389, p<0.001\right)$ as well as the number of families caught per card $\left(F_{1,55}=4.158, p<0.001\right.$, Table 2$)$. Both the number of individuals and the number of families were found to be enhanced by increasing plant cover (Fig. 4). Linear Mixed Models could be used to describe the relationship between plant cover and insect community (Shannon-Wiener diversity, mean individuals per card, and family number per card) (Fig. 4). However, both the ANPP and water content of plants had no significant linear relationship with either the mean number of individuals per card or the number of families per card) (Fig. 4).

\section{Discussion}

Our experiments indicated that both plant cover had a more pronounced effect on insect community family diversity than did ANPP, and may be an underlying mechanism of the positive relationship between plant species richness and insect diversity ( $P a n, 2016)$. Thus, the effects of a plant community on the corresponding insect community do not occur simply due to increased ANPP in more diverse habitats like meadow steppe (Hamback et al., 2014). An increase in available resources may be another driving force affecting ecosystem structure, which are non-additive and cascade across trophic levels to structures associated with insect community (Camarota et al., 2015).

The mixture of insect individuals from different families was found to be different for each steppe type, as environmental factors shaped the insect community. Our experiments suggests that the interspecific variation (functional group) of plants should be incorporated into current ecological theory, which could explain the positive correlation between particular plant species and ecological function provided by functional insect groups (Soliveres et al., 2015; Moran et al., 2016). In addition, certain insect groups could be used to indicate changes in environmental factors (Forrest, 2015). For example, some species in Tenebrionidae (Coleoptera) are indicators of soil desertification (Fattorini and Salvati, 2014; Zhao et al., 2014), while the abundance of Muscidae (Diptera) could be used to monitor water quality due to its sensitivity to environmental quality (Paisley et al., 2014) and pollinating insects could reveal pollution level and give some clues as to the broader plant community (Kovacs-Hostyanszki et al., 2017). Desirable ecosystem functions could therefore potentially be enhanced by the addition of particular plant functional groups. Thus, the functional groups of both insect and plant communities should be emphasized to determine their ecological functions (Eskildsen et al., 2015).

Given the focus of conservation efforts on how to increase ANPP in steppe grassland in China, our work suggests that plant cover (and diversification) can no longer be overlooked in future conservation measures. Although the relationship between vegetation type and insect community has not come to a consistent reorganization across multiple steppe regions, it is well accepted that diversified plant communities (high plant cover) generally enhance the abundance and species-level diversity of the associated insect community (Zhao et al., 2015a, 2015b; Moreira et al., 2016). In our experiment, ANPP had no significant effects on insect community. This might be because of the dominance in steppe desert and desert steppe of perennial, ultra-arid-adapted shrubs due to the low precipitation. In comparison, meadow steppe and typical steppe were dominated by annual grass (Liu et al., 2015). Also, woody tissue in perennial shrubs in desert steppe had a higher ANPP than the herbaceous plants and grasses in meadow and typical steppe. Some dominant plant species had a large ANPP but do not provide important food resources to insects (Genrich et al., 2017). For example, there are few insects on Artemisia scoparia Waldst. et Kit. due to the low nutrition and poor palatability of this plant for insects.

\section{Conclusions}

In China, enclosure has been an important conservation strategy for enhancing ANPP and biodiversity. However, we found that plant cover played a more important role in insect diversity than ANPP. The plant species composition in different steppe types could be used to detect environmental changes and ecosystem function (Tarrason et al., 2016). The functional groups of plant and insect communities should be considered to help in defining the specific ecological functions in further research. Supplemental sowing in steppe habitats may be another strategy to enhance biodiversity and achieve sustainable management (Briske et al., 2015).

\section{Conflict of interest}

The authors declare that they have no conflict of interests.

\section{Acknowledgements}

We would like to thank Zhao Yu, Yun Li and Feng Wang from Ningxia Grassland Station for their assistance in the field investigation. We would also like to thank Profs. Chaodong Zhu and Zeqing Niu from Institute of Zoology, Chinese Academy of Sciences, Profs. Huanli Xu and Xingyue Liu from China Agricultural University for insect identification. We would also thank to the Prof. Liyuan Gao from Ningxia Academy of Agriculture and Forestry whose comments have significantly improved the quality of this manuscript. We also thank to the two autonomous reviewers for their invaluable comments for our research. This work was supported by Grant (NKYZ-16-1003) from 123 Industry Integration Development for Demonstration Project of Science and Technology Innovation in Ningxia of China and the National Natural Science Foundation of China (No. 31770453).

Table 2

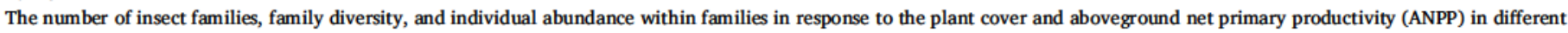

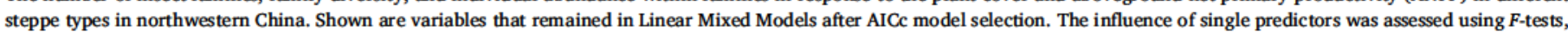
comparing the model with and without the respective variables. Levels of significance: ${ }^{* * *} p<0.001,{ }^{* *} p<0.01,{ }^{*} p<0.05$.

\begin{tabular}{|c|c|c|c|c|c|}
\hline Variables & Optional regression equation & $F_{1,54}$ & $P$-value & Adjusted $\mathrm{R}^{2}$ & AIC \\
\hline Family diversity of insects & Insect diversity $=0.8234+0.0008$ cover $^{*}$ & 5.076 & 0.028 & 0.069 & -328.71 \\
\hline Abundance of insects & Mean individuals $=15.1991+0.9642$ cover $* * *$ & 10.93 & $<0.001$ & 0.249 & 391.04 \\
\hline Family richness & Family number $=13.2788+0.1886$ cover $^{* * *}$ & 17.29 & $<0.001$ & 0.229 & 214.31 \\
\hline
\end{tabular}



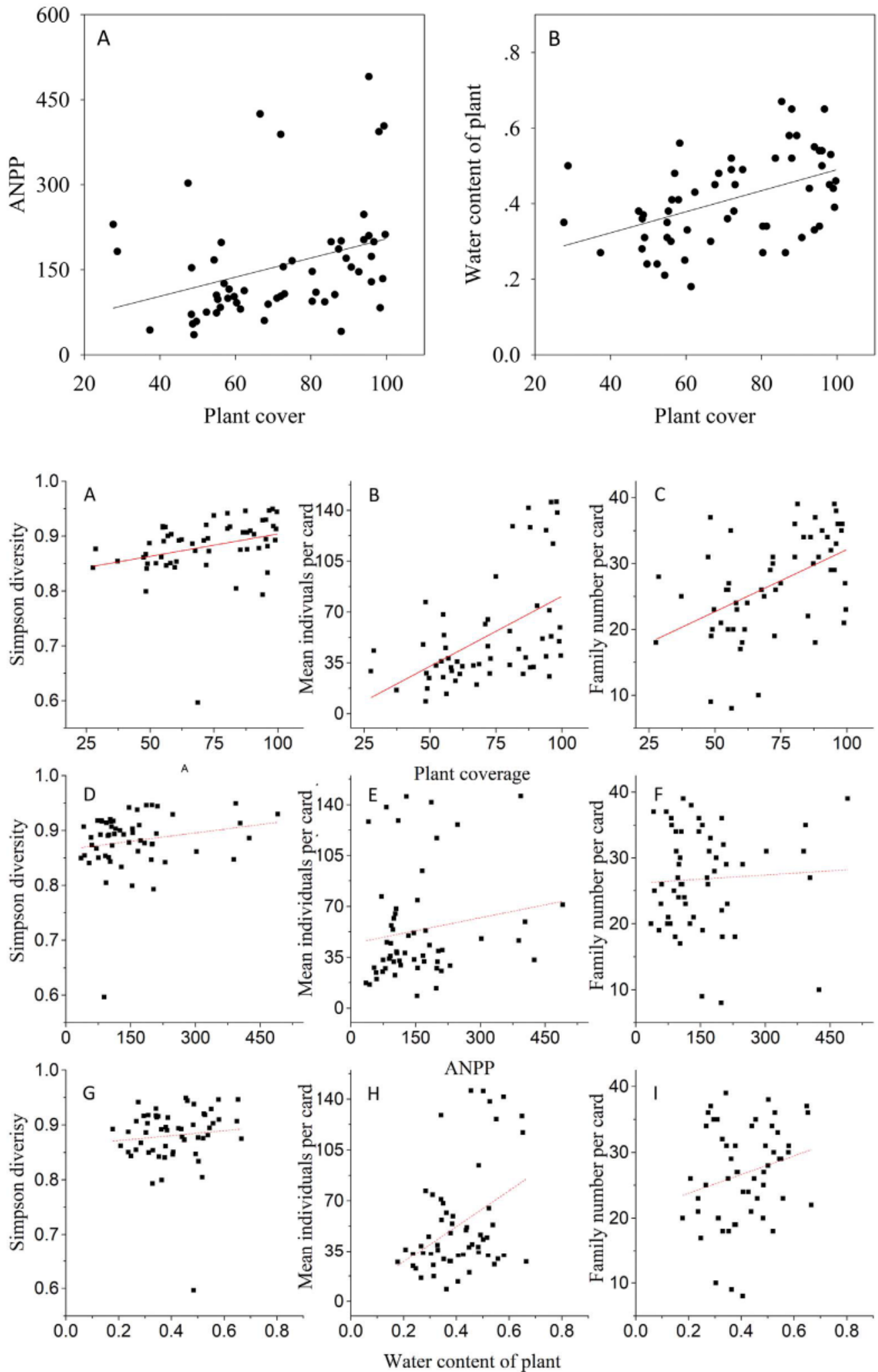

Fig. 3. The effects of plant species diversity on aboveground net primary productivity (ANPP) (A) and the water content of the plants (B).

Fig. 4. Effects of plant cover, aboveground net primary productivity, and water content of plants on insect community (solid lines indicated that there was a significant regression equation, dash lines indicate that there was no significant regression equation, A-C: the effects of plant cover on diversity, mean individuals per card, and family number of insect community, D-F: the effects of ANPP on diversity, mean individuals per card, and family number of insect community, G-I: the effects of water content on diversity, mean individuals per card, and family number of insect community).

\section{References}

Barral, M.P., Benayas, J.M.R., Meli, P., Maceira, N.O., 2015. Quantifying the impacts of ecological restoration on biodiversity and ecosystem services in agroecosystems: a global meta-analysis. Agric. Ecosyst. Environ. 202, 223-231.

Branco, M., Brockerhoff, E.G., Castagneyrol, B., Orazio, C., Jactel, H., 2015. Host range expansion of native insects to exotic trees increases with area of introduction and the presence of congeneric native trees. J. Appl. Ecol. 52, 69-77.

Briske, D.D., Zhao, M.L., Han, G.D., Xiu, C.B., Kemp, D.R., Willms, W., Havstad, K., Kang,
L., Wang, Z.W., Wu, J.G., Han, X.G., Bai, Y.F., 2015. Strategies to alleviate poverty and grassland degradation in Inner Mongolia: intensification vs production efficiency of livestock systems. J. Environ. Manag. 152, 177-182.

Camarota, F., Powell, S., Vasconcelos, H.L., Priest, G., Marquis, R.J., 2015. Extrafloral nectaries have a limited effect on the structure of arboreal ant communities in a Neotropical savanna. Ecology 96, 231-240.

Deak, B., Tothmeresz, B., Valko, O., Sudnik-Wojcikowska, B., Moysiyenko, I.L., Bragina, T.M., Apostolova, I., Dembicz, I., Bykov, N.I., Torok, P., 2016. Cultural monuments and nature conservation: a review of the role of kurgans in the conservation and restoration of steppe vegetation. Biodivers. Conserv. 25, 2473-2490. 
Dengler, J., Janisova, M., Torok, P., Wellstein, C., 2014. Biodiversity of Palaearctic grasslands: a synthesis. Agric. Ecosyst. Environ. 182, 1-14.

Ebeling, A., Pompe, S., Baade, J., Eisenhauer, N., Hillebrand, H., Proulx, R., Roscher, C., Schmid, B., Wirth, C., Weisser, W.W., 2014. A trait-based experimental approach to understand the mechanisms underlying biodiversity-ecosystem functioning relationships. Basic Appl. Ecol. 15, 229-240.

Eo, J., Kim, M.H., Bang, H.S., Choi, S.K., Na, Y.E., Cho, K.J., Oh, Y.J., Yang, D., Park, S., 2016. Effects of climate and landscape heterogeneity on the distribution of ground beetles (Coleoptera: Carabidae) in agricultural fields. J. Asia Pac. Entomol. 19, 1009-1014.

Eskildsen, A., Carvalheiro, L.G., Kissling, W.D., Biesmeijer, J.C., Schweiger, O., Hoye, T.T., 2015. Ecological specialization matters: long-term trends in butterfly species richness and assemblage composition depend on multiple functional traits. Divers. Distrib. 21, 792-802.

Fanin, N., Fromin, N., Buatois, B., Hattenschwiler, S., 2013. An experimental test of the hypothesis of non-homeostatic consumer stoichiometry in a plant littermicrobe system. Ecol. Lett. 16, 764-772.

Fattorini, S., Salvati, L., 2014. Tenebrionid beetles as proxy indicators of climate aridity in a Mediterranean area. Ecol. Indic. 38, 256-261.

Forister, M.L., Novotny, V., Panorska, A.K., Baje, L., Basset, Y., Butterill, P.T., Cizek, L., Coley, P.D., Dem, F., Diniz, I.R., Drozd, P., Fox, M., Glassmire, A.E., Hazen, R., Hrcek, J., Jahner, J.P., Kaman, O., Kozubowski, T.J., Kursar, T.A., Lewis, O.T., Lill, J., Marquis, R.J., Miller, S.E., Morais, H.C., Murakami, M., Nickel, H., Pardikes, N.A., Ricklefs, R.E., Singer, M.S., Smilanich, A.M., Stireman, J.O., Villamarin-Cortez, S., Vodka, S., Volf, M., Wagner, D.L., Walla, T., Weiblen, G.D., Dyer, L.A., 2015. The global distribution of diet breadth in insect herbivores. P. Natl. Acad. Sci. USA 112, 442-447.

Forrest, J.R.K., 2015. Plant-pollinator interactions and phenological change: what can we learn about climate impacts from experiments and observations? Oikos 124, 4-13.

Fujii, S., Mori, A.S., Koide, D., Makoto, K., Matsuoka, S., Osono, T., Isbell, F., 2017. Disentangling relationships between plant diversity and decomposition processes under forest restoration. J. Appl. Ecol. 54, 80-90.

Genrich, C.M., Mello, M.A.R., Silveira, F.A.O., Bronstein, J.L., Paglia, A.P., 2017. Duality of interaction outcomes in a plant-frugivore multilayer network. Oikos 126, 361-368.

Haddad, N.M., Crutsinger, G.M., Gross, K., Haarstad, J., Knops, J.M.H., Tilman, D., 2009. Plant species loss decreases arthropod diversity and shifts trophic structure. Ecol. Lett. 12, 1029-1039.

Hamback, P.A., Inouye, B.D., Andersson, P., Underwood, N., 2014. Effects of plant neighborhoods on plant-herbivore interactions: resource dilution and associational effects. Ecology 95, 1370-1383.

Kovacs-Hostyanszki, A., Espindola, A., Vanbergen, A.J., Settele, J., Kremen, C., Dicks, L.V., 2017. Ecological intensification to mitigate impacts of conventional intensive land use on pollinators and pollination. Ecol. Lett. 20, 673-689.

Lange, M., Eisenhauer, N., Sierra, C.A., Bessler, H., Engels, C., Griffiths, R.I., MelladoVazquez, P.G., Malik, A.A., Roy, J., Scheu, S., Steinbeiss, S., Thomson, B.C., Trumbore, S.E., Gleixner, G., 2015. Plant diversity increases soil microbial activity and soil carbon storage. Nat. Commun. 6.

Li, Y.B., Fan, M.M., Li, W.J., 2015. Application of payment for ecosystem services in China's rangeland conservation initiatives: a social-ecological system perspective. Rangel. J. 37, 285-296.

Liere, H., Jha, S., Philpott, S.M., 2017. Intersection between biodiversity conservation, agroecology, and ecosystem services. Agroecol. Sustain. Food 41, 723-760.

Liu, B., Zhao, W.Z., Liu, Z.L., Yang, Y.T., Luo, W.C., Zhou, H., Zhang, Y.Y., 2015. Changes in species diversity, aboveground biomass, and vegetation cover along an afforestation successional gradient in a semiarid desert steppe of China. Ecol. Eng. 81, 301-311.

Maser, C., 2013. Effects of insects on ecosystem services. Soc. Environ. Sustain. 1, 233-273.

Moran, E.V., Hartig, F., Bell, D.M., 2016. Intraspecific trait variation across scales: implications for understanding global change responses. Glob. Chang. Biol. 22, 137-150.

Moreira, X., Abdala-Roberts, L., Rasmann, S., Castagneyrol, B., Mooney, K.A., 2016. Plant diversity effects on insect herbivores and their natural enemies: current thinking, recent findings, and future directions. Curr. Opin Insect. Sci. 14, 1-7.

Paisley, M.F., Trigg, D.J., Walley, W.J., 2014. Revision of the biological monitoring working party (Bmwp) score system: derivation of present-only and abundance-related scores from field data. River Res. Appl. 30, 887-904.

Palmer, M.A., Hondula, K.L., Koch, B.J., 2014. Ecological restoration of streams and rivers: shifting strategies and shifting goals. Annu. Rev. Ecol. Evol. Syst. 45, 247-269.

Pan, X.B., 2016. Application of fundamental equations to species-area theory. BMC Ecol. 16.

Prieto, I., Violle, C., Barre, P., Durand, J.L., Ghesquiere, M., Litrico, I., 2015. Complementary effects of species and genetic diversity on productivity and stability of sown grasslands. Nat. Plants 1.

Qin, D.H., Tao, S., Dong, S.C., Luo, Y., Li, F., Yang, W.Z., 2016. Climate, environmental, and socioeconomic characteristics of China. Spr. Environ. Sci. Eng. 1, 1-27.

R Development Core Team, 2016. R: A language and environment for statistical computing. Foundation for Statistical Computing, Vienna, Austria. http://www.Rproject.org, version 3.4.1..

Rangel-Landa, S., Casas, A., Davila, P., 2015. Facilitation of Agave potatorum: an ecological approach for assisted population recovery. Forest Ecol. Manag. 347, 57-74.

Richards, L.A., Dyer, L.A., Forister, M.L., Smilanich, A.M., Dodson, C.D., Leonard, M.D., Jeffrey, C.S., 2015. Phytochemical diversity drives plant-insect community diversity. P. Natl. Acad. Sci. USA 112, 10973-10978.

Rossetti, M.R., Tscharntke, T., Aguilar, R., Batary, P., 2017. Responses of insect herbivores and herbivory to habitat fragmentation: a hierarchical meta-analysis. Ecol. Lett. 20, 264-272.

Santana, J., Reino, L., Stoate, C., Moreira, F., Ribeiro, P.F., Santos, J.L., Rotenberry, J.T., Beja, P., 2017. Combined effects of landscape composition and heterogeneity on farmland avian diversity. Ecol. Evol. 7, 1212-1223.

Soliveres, S., Smit, C., Maestre, F.T., 2015. Moving forward on facilitation research: response to changing environments and effects on the diversity, functioning and evolution of plant communities. Biol. Rev. 90, 297-313.

Souza, L., Zelikova, T.J., Sanders, N.J., 2016. Bottom-up and top-down effects on plant communities: nutrients limit productivity, but insects determine diversity and composition. Oikos $125,566-575$.

Tardif, A., Shipley, B., Bloor, J.M.G., Soussana, J.F., 2014. Can the biomass-ratio hypothesis predict mixed-species litter decomposition along a climatic gradient? Ann. Bot-London 113, 843-850.

Tarrason, D., Ravera, F., Reed, M.S., Dougill, A.J., Gonzalez, L., 2016. Land degradation assessment through an ecosystem services lens: integrating knowledge and methods in pastoral semi-arid systems. J. Arid Environ. 124, 205-213.

Yachi, S., Loreau, M., 1999. Biodiversity and ecosystem productivity in a fluctuating environment: the insurance hypothesis. P. Natl. Acad. Sci. USA 96, 1463-1468.

Zhang, L., Luo, Z.H., Mallon, D., Li, C.W., Jiang, Z.G., 2017. Biodiversity conservation status in China's growing protected areas. Biol. Conserv. 210, 89-100.

Zhao, Z.H., Shi, P.J., Men, X.Y., Ouyang, F., Ge, F., 2013. Effects of crop species richness on pest-natural enemy systems based on an experimental model system using a microlandscape. Sci. China Life Sci. 56, 758-766.

Zhao, H.L., Li, J., Liu, R.T., Zhou, R.L., Qu, H., Pan, C.C., 2014. Effects of desertification on temporal and spatial distribution of soil macro-arthropods in Horqin sandy grassland, Inner Mongolia. Geoderma 223, 62-67.

Zhao, Z.H., Hui, C., Li, Z.H., Li, B.L., 2015a. Habitat heterogeneity stabilizes the spatia and temporal interactions between cereal aphids and parasitic wasps. Basic Appl. Ecol. 16, 510-518.

Zhao, Z.H., Sandhu, H.S., Gao, F., He, D.H., 2015b. Shifts in natural enemy assemblages resulting from landscape simplification account for biocontrol loss in wheat fields. Ecol. Res. 30, 493-498.

Zhao, Z.H., Reddy, G.V.P., Hui, C., Li, B.L., 2016. Approaches and mechanisms for ecologically based pest management across multiple scales. Agric. Ecosyst. Environ. 230, 199-209.

Zhu, H., Wang, D.L., Guo, Q.F., Liu, J., Wang, L., 2015. Interactive effects of large herbivores and plant diversity on insect abundance in a meadow steppe in China. Agric. Ecosyst. Environ. 212, 245-252. 